\title{
O metifenidato no Brasil: uma década de publicações
}

\author{
Methylphenidate in Brazil: a decade of publications
}

Claudia Itaborahy ${ }^{1}$

Francisco Ortega ${ }^{1}$
${ }^{1}$ Instituto de Medicina Social, Universidade do Estado do Rio de Janeiro. Rua São Francisco Xavier 624/7o blocos D e E, Maracanã. 20550-900 Rio de Janeiro RJ.

claudiaitaborahy@gmail.com

\begin{abstract}
Methylphenidate is frequently associated with Attention Deficit Hyperactivity disor$\operatorname{der}(A D H D)$, though this psychostimulant has been on the market in Switzerland, Germany and the US since the 1950s. After its association with $A D H D$, Ritalin has become the world's most widely used psychostimulant. The scope of this article is to present the results of an analysis of publications concerning the use of Methylphenidate in Brazil over a decade. It seeks to understand how the information is presented or omitted in the different printed materials. For the analysis, the most important Brazilian psychiatric journals as well as major Brazilian newspapers and magazines for the general public for the 1998-2008 period were consulted. One important point that resulted from analysis of the empirical material was the participation of pharmaceutical laboratories in the funding of research groups on $A D H D$. The findings reveal several controversial issues in the publications, such as the combination of drugs and psychotherapy, as well as issues of addiction and over-prescription.
\end{abstract}

Key words Methylphenidate, Attention Deficit Hyperactivity Disorder, Publications
Resumo O metilfenidato é um estimulante comercializado desde os anos 50 na Suíça, na Alemanha e nos EUA. Mas foi somente a partir de sua associação com o Transtorno do Déficit de Atenção e Hiperatividade (TDAH) que suas vendas alavancaram, tornando-se o estimulante mais consumido no mundo. Este artigo tem por objetivo apresentar os resultados de uma análise das publicações brasileiras sobre os usos do metilfenidato no Brasil, ao longo da última década. Com isto, visa compreender como as informações são apresentadas ou omitidas nos diferentes espaços de divulgação impressa. Para tal análise, foram pesquisadas publicações científicas, nos principais periódicos de psiquiatria brasileiros, e reportagens de jornais e revistas nacionais destinados ao público em geral. A pesquisa inclui as publicações do período de 1998 a 2008. Destaca-se como ponto relevante da análise a importante participação dos laboratórios no financiamento dos grupos e pesquisas sobre TDAH. Os achados indicam que a combinação do uso do medicamento com psicoterapias, a dependência do medicamento e a ideia de que existe excesso de prescrição no Brasil são temas controversos nas publicações analisadas.

Palavras-chave Metilfenidato, Transtorno do Déficit de Atenção com hiperatividade, Publicações 


\section{Introdução}

O metilfenidato, usualmente prescrito para crianças e adultos diagnosticados com o Transtorno do Déficit de Atenção e Hiperatividade (TDAH), foi sintetizado em 1944, na Suíça, e patenteado em 1954. Ele começou a ser comercializado neste mesmo ano na Suíça como um psicoestimulante leve, e na Alemanha, onde não havia necessidade de prescrição médica para a compra. Passou a ser comercializado nos EUA em 1956 e no Canadá em 1979¹. No Brasil, segundo informado pela Agência Nacional de Vigilância Sanitária (ANVISA), o início da comercialização teria sido em $1998^{2}$. Contudo, no artigo de Almeida et al. ${ }^{3}$, existe referência de comercialização nacional anterior a esta data.

Para que um médico prescreva o metilfenidato no Brasil, é necessário o bloco amarelo de receita, disponibilizado na Vigilância Sanitária. A receita amarela tem validade de 30 dias e fica retida na farmácia, que deve encaminhar às autoridades sanitárias relatórios mensais de venda, balanços trimestrais e anuais de compra e venda.

O metilfenidato é hoje o psicoestimulante mais consumido no mundo, mais que todos os outros estimulantes somados. Segundo o relatório da Organização das Nações Unidas sobre produção de psicotrópicos ${ }^{4}$, sua produção mundial passou de 2,8 toneladas em 1990 para quase 38 toneladas em 2006.

Das 38 toneladas produzidas em 2006, 34,6 foram produzidas pelos Estados Unidos, que também são os maiores consumidores do estimulante. Naquele ano, o consumo mundial de metilfenidato foi de 35,8 toneladas, $82,2 \%$ foram consumidos pelos EUA. Segundo o relatório, o grande aumento do consumo de metilfenidato, principalmente nos EUA, se deve à sua vinculação ao TDAH e à intensa publicidade do medicamento voltada diretamente aos consumidores norte-americanos.

Em 1970, já se estimava que 150.000 crianças norte-americanas faziam uso de estimulantes. Em 1987, esta estimativa passou para 750.000 crianças em idade escolar. Em 1995, este número alcançava mais de 2,6 milhões 5 .

No Brasil, o consumo também vem crescendo ao longo dos anos. No ano 2000, o consumo nacional de metilfenidato foi de $23 \mathrm{~kg}^{6}$. A produção brasileira passou de $40 \mathrm{~kg}$ em 2002 para 226 kg em 2006. Além disso, em 2006, o Brasil importou $91 \mathrm{~kg}$ do estimulante ${ }^{4}$.

Diller $^{5}$ apresenta algumas hipóteses para o crescimento da produção e do consumo do me- tilfenidato. Uma, são as mudanças nos critérios diagnósticos que tendem sempre a ampliar o grupo de pessoas que se inserem no diagnóstico de TDAH, aumentando consequentemente os usuários em potencial de estimulantes. Além disso, a pressão sobre o desempenho das crianças teria aumentado desproporcionalmente ao suporte social dado a elas. O autor também sugere que, cada vez mais, a sociedade tem interpretado problemas de desempenho como doenças. Definir incapacidades faz com que estas pessoas possam não enfrentar discriminação, além de terem benefícios de serviços especiais. A análise realizada por Diller tem como foco o consumo norte-americano do estimulante.

O presente trabalho tem como objetivo analisar as publicações sobre o metilfenidato no Brasil desde o ano de sua regulamentação, 1998, como fornecido pela Anvisa, até 2008, a fim de verificar que aspectos foram enunciados e quais ganharam relevo nos diferentes veículos de produção e divulgação do conhecimento ao longo desta década. Espera-se, com isso, contribuir para a compreensão da situação brasileira do conhecimento público do metilfenidato.

\section{Métodos}

Com o objetivo de analisar o que é dito no Brasil sobre o metilfenidato, o que justifica seu uso e o que o desconsidera como terapêutica necessária, foi realizado levantamento de todas as publicações nos jornais e revistas voltados para o público em geral bem como artigos em periódicos especializados. O período analisado foi de 1998 até final de novembro de 2008.

Os artigos foram pesquisados nos cinco periódicos brasileiros de psiquiatria indexados na base Scielo. As publicações destinadas ao público em geral foram pesquisadas nas duas revistas semanais, que abordam assuntos gerais, com maior tiragem nacional, bem como nos três jornais também com a maior tiragem nacional ${ }^{7}$. Optou-se por utilizar as publicações com maior tiragem por compreender que estas alcançam maior número de leitores que as demais.

Os periódicos brasileiros de psiquiatria analisados foram a Revista Brasileira de Psiquiatria (RBP), o Jornal Brasileiro de Psiquiatria (JBP), os Arquivos de Neuropsiquiatria (ANP), a Revista de Psiquiatria do Rio Grande do Sul (RPRS) e a Revista de Psiquiatria Clínica (RPC). Os jornais analisados foram a Folha de São Paulo, o Jornal O Globo e o Jornal Extra, além das duas revistas 
semanais de maior tiragem, a Revista Veja e a Revista Época.

Ao todo, foram identificadas 103 publicações, sendo 72 reportagens publicadas nos jornais e revistas de grande circulação e 31 artigos dos periódicos de psiquiatria.

A busca foi realizada primeiramente com as palavras-chave "metilfenidato" e seu nome comercial mais conhecido, "Ritalina", com seus respectivos em inglês. Contudo, a grande maioria das publicações tinha como temática principal o Transtorno do Déficit de Atenção e Hiperatividade (TDAH). Além disso, muitas publicações sobre TDAH abordavam questões referentes ao metilfenidato sem citá-lo explicitamente. Com isso, foram incluídos na amostra os artigos sobre TDAH que discutem o tratamento medicamentoso para o transtorno. Nestes artigos, o metilfenidato aparece como "uso de estimulantes para sintomas de TDAH", "tratamento medicamentoso para hiperatividade", "psicoestimulantes para déficit de atenção”, etc.

Os artigos e reportagens sobre o metilfenidato foram analisados a partir de categorias para análise qualitativa. As mesmas categorias foram utilizadas para os artigos científicos e para as reportagens destinadas ao público em geral.

Na primeira leitura do material empírico cada tema abordado nas publicações foi separado em categorias. Posteriormente, algumas destas foram agrupadas em três principais temas que serão abordados neste artigo: benefícios apresentados, efeitos adversos relatados e excesso/falta de prescrição do medicamento.

Para melhor organização da análise qualitativa foi utilizado o software $\mathrm{NVivo}^{\circledR}$, que permite ao pesquisador criar categorias de análise e codificar o conteúdo dos artigos analisados. Este software auxilia o pesquisador apenas na organização dos dados e no acesso a eles. Toda criação de temas, análise e codificação das publicações é feita pelo pesquisador.

\section{Resultados}

\section{Descrição inicial dos dados}

A partir das publicações nos periódicos científicos, foi observado que, dos 31 artigos analisados, vinte e sete foram direta ou indiretamente financiados pelos laboratórios fabricantes do metilfenidato no Brasil (Novartis e Janssen-Cilag), pagando as pesquisas, por patrocínio dos grupos ou com autores dos artigos sendo repre- sentantes dos laboratórios. Apenas nove apresentam conflitos de interesse, sendo que em um destes o financiamento da Novartis é publicado apenas como "agradecimentos".

No que tange às 72 reportagens voltadas para o público em geral, foi observado uma modificação da abordagem dos jornalistas sobre o uso do estimulante comparando as reportagens mais antigas com as publicadas nos últimos artigos analisados. As dos anos iniciais se referem muito mais a uma apresentação do que é o metilfenidato e "como tratar o Déficit de Atenção". Algumas destas são acompanhadas por "testes" e tabelas com critérios diagnósticos resumidos, para que o leitor descubra se ele tem ou não TDAH. Ao longo dos anos, este tipo de reportagem vai dando lugar a fortes debates sobre a existência do Transtorno do Déficit de Atenção e a necessidade do uso de medicamentos, assim como outros usos do metilfenidato. É a partir de 2005 e 2006 que as reportagens que levantam questionamentos sobre o uso do estimulante se tornam mais frequentes.

Outro dado observado foi uma repetição de temas nas revistas e jornais de ampla divulgação numa mesma semana. Isto se deve, principalmente, ao fato da imprensa brasileira reproduzir frequentemente matérias já publicadas nos jornais e revistas estrangeiros, principalmente norte-americanos e ingleses. As pesquisas publicadas no exterior parecem ter maior relevância na imprensa nacional do que as brasileiras. Os autores nacionais são convidados a comentar as pesquisas internacionais publicadas. Todas as publicações que apresentam resultados de pesquisas se referem apenas às estrangeiras.

Das 72 reportagens analisadas, 18 são traduções ou são totalmente referidas a reportagens e pesquisas estrangeiras, e outras 24 fazem referência a pesquisas internacionais. Apenas 30 reportagens não citavam pesquisas internacionais.

A narcolepsia, outro diagnóstico para o qual o estimulante é indicado, além do TDAH, aparece citada em apenas um artigo científico. Nenhuma reportagem tratou do uso do metilfenidato para tratamento desse problema.

\section{Categorias de análise}

\section{Benefícios do uso do metilfenidato apresentados nas publicações}

Nesta categoria de análise se incluem os benefícios apresentados que, em geral, justificam o uso do metilfenidato em detrimento de outro fármaco ou outra terapêutica, assim como os 
efeitos positivos da sua utilização. Esta categoria de análise está relacionada à questão da eficácia do medicamento.

Dos trinta e um artigos dos periódicos de psiquiatria, vinte e três (74\%) apresentam benefícios do uso do metilfenidato. Destes, cinco não se referem ao uso de metilfenidato para tratamento do TDAH, enquanto os outros dezoito abordam os benefícios para a cura do transtorno do déficit de atenção. Nestes últimos, ressaltam-se os efeitos do estimulante na remissão dos sintomas que caracterizam o Transtorno do Déficit de Atenção. Também foram relatados outros benefícios como a baixa toxidade, a segurança clínica, a boa tolerância do medicamento, sua superioridade quando comparado ao placebo e em relação ao tratamento psicoterápico (terapia cognitivo-comportamental), ou mesmo sua superioridade em relação ao tratamento combinado (fármaco + terapia cognitivo-comportamental), melhoria do desempenho acadêmico, melhoria na qualidade do sono e no desempenho em testes de processamento auditivo em crianças com TDAH após o uso do medicamento (Quadro 1).

A eficácia do medicamento, embora vinculada a dados estatísticos, não se define necessariamente pelos resultados. Foram encontradas pesquisas em que, nos resultados, a magnitude da resposta ao medicamento é de pequena a mediana, e ainda assim a conclusão é pela eficácia.

A mencionada superioridade do uso do medicamento em relação ao medicamento somado à terapia cognitivo-comportamental (TCC) levanta a questão se a terapia cognitivo-comportamental reduziria o efeito do medicamento.

Outro benefício relatado nos artigos analisados é o efeito “antidependência”, ou seja, o metilfenidato diminuiria os riscos de Transtorno por uso de substâncias psicoativas (TUSP).

O benefício "antidependência" é frequentemente apresentado como resposta aos questionamentos sobre uma possível dependência do uso do medicamento. Ou seja, este benefício tem um duplo sentido: o metilfenidato não causa dependência e ainda evita abuso de outras substâncias no futuro.

A concepção de que o metilfenidato não causa dependência é controversa, pelo menos o que tange seu uso em longo prazo. Segundo a Associação Médica Brasileira e o Conselho Federal de Medicina ${ }^{25}$, o metilfenidato é uma anfetamina de uso médico, e pode causar dependência, assim como qualquer anfetamina. Esta indicação também é encontrada na bula do medicamento.
A redução da possibilidade do uso de substâncias psicoativas parece estar ligada à concepção do TDAH como um fator de risco para o desenvolvimento do abuso de drogas. O benefício do medicamento na redução dos sintomas reduziria, consequentemente, os riscos próprios do transtorno. Para Romano e Szobot ${ }^{23}$, o metilfenidato de ação prolongada é o mais recomendado para a comorbidade TDAH-TUSP, entretanto, ele é sempre comparado ao placebo, e não ao seu similar de ação imediata.

Embora os autores não tenham encontrado nenhum resultado da eficácia do medicamento na prevenção do uso de drogas, ainda sim a conclusão é pela eficácia na prevenção, por diminuir os sintomas do TDAH, principalmente o metilfenidato de liberação controlada, que evitaria o abuso do medicamento. Cabe ressaltar que os dois autores são palestrantes e consultores do laboratório fabricante do metilfenidato de ação prolongada.

Segundo Romano e Szobot ${ }^{23}$ :

existem poucos estudos abertos e controlados que tenham avaliado resultados do tratamento farmacológico na comorbidade TUSP-TDAH [...].Um ensaio clínico brasileiro [...], controlado com placebo, [...] em uma amostra ambulatorial de adolescentes com TUSP [...]; o metilfenidato de liberação controlada SODAS mostrou-se significativamente superior ao placebo em reduzir os sintomas de TDAH e melhorar o funcionamento global dos adolescentes participantes do estudo. Embora não tenha havido efeito sobre o TUSP, é possível que isso se deva ao curto tempo de duração do estudo (seis semanas) e à falta de uma abordagem terapêutica simultânea específica [...].

A partir destes dados, a indicação dos autores é pelo uso do estimulante no tratamento de TDAH-TUSP. A principal contribuição do medicamento seria a redução dos sintomas do TDAH, não sendo apresentada nenhuma outra relação do metilfenidato com a prevenção do uso de substâncias psicoativas.

Nas 72 reportagens brasileiras sobre o metilfenidato no mesmo período analisado, --29 apresentam os benefícios do seu uso (40\%). Nestas, o apresentado com maior frequência também corresponde à redução dos sintomas do TDAH com o uso do estimulante. A melhoria do desempenho escolar é muito citada, e se relaciona com a remissão dos sintomas de falta de atenção, hiperatividade e impulsividade.

Nestas reportagens também são enfatizadas a redução da possibilidade de uso de drogas no futuro. Este possível benefício do uso estimulan- 
Quadro 1. Benefícios do uso do metilfenidato.

\begin{tabular}{|c|c|c|}
\hline $\begin{array}{l}\text { Benefícios para } \\
\text { usos diversos }\end{array}$ & Referências & Detalhes \\
\hline $\begin{array}{l}\text { Melhoria clínica em } \\
\text { distúrbios do sono }\end{array}$ & $\begin{array}{l}\text { Bittencourt et al. }{ }^{8} \\
\text { Lucchesi et al. }\end{array}$ & $\begin{array}{l}\text { O uso do metilfenidato para os distúrbios do sono, } \\
\text { segundo estes artigos, propicia um sono de melhor } \\
\text { qualidade e consequente melhora no } \\
\text { comportamento diurno (bom humor, diminuição } \\
\text { da fadiga) e da cognição. }\end{array}$ \\
\hline $\begin{array}{l}\text { Melhoria cognitiva em } \\
\text { traumatismo crânio- } \\
\text { encefálico }\end{array}$ & Rocha et al. ${ }^{10}$ & $\begin{array}{l}\text { Os autores relatam a melhoria cognitiva de } \\
\text { um paciente (concentração na leitura, capacidade } \\
\text { de manter atenção em conversas, filmes, etc.) após } \\
\text { dois meses de tratamento. }\end{array}$ \\
\hline $\begin{array}{c}\text { Melhoria clínica da } \\
\text { apatia em pacientes com } \\
\text { Alzheimer }\end{array}$ & $\begin{array}{l}\text { Teixeira Júnior e } \\
\text { Caramelli }^{11} \text {. }\end{array}$ & $\begin{array}{l}\text { Melhora clínica da apatia, sem melhora dos } \\
\text { déficits cognitivos. }\end{array}$ \\
\hline Benefícios para TDAH & Referências & Exemplos \\
\hline Eficácia & $\begin{array}{l}\text { Pastura e Mattos }{ }^{12} \text {; Carlini } \\
\text { et al. } .^{13} ; \text { Rohde et al. } .^{14} ; \\
\text { Serenreich e Mattos } \\
\text { Louzã e Mattos }\end{array}$ & $\begin{array}{l}\text { "A eficácia clínica do metilfenidato já foi } \\
\text { comprovada em mais de } 1.500 \text { estudos clínicos } \\
\text { nos últimos } 40 \text { anos". (Pastura e Mattos }{ }^{12} \text { ) }\end{array}$ \\
\hline Baixa toxidade & Carlini et al. ${ }^{13}$ & \\
\hline Boa tolerância & $\begin{array}{l}\text { Pastura e Mattos }{ }^{12} \\
\text { Scheuer e Andrade }\end{array}$ & \\
\hline $\begin{array}{l}\text { Superioridade em } \\
\text { relação ao placebo }\end{array}$ & Louzã e Mattos ${ }^{16}$ & \\
\hline $\begin{array}{l}\text { Superioridade do } \\
\text { tratamento } \\
\text { medicamentoso em } \\
\text { relação ao tratamento } \\
\text { psicoterápico (TCC) ou } \\
\text { mesmo em relação ao } \\
\text { tratamento combinado } \\
\text { (medicação + TCC). }\end{array}$ & $\begin{array}{l}\text { Serenreich e Mattos }{ }^{15} \text {; } \\
\quad \text { Rohde et al. }{ }^{14}\end{array}$ & \\
\hline $\begin{array}{l}\text { Benéfico no } \\
\text { acompanhamento por } \\
\text { longo tempo por } \\
\text { necessitar de pouco } \\
\text { ajuste da dose. }\end{array}$ & Scheuer e Andrade ${ }^{17}$ & \\
\hline $\begin{array}{l}\text { As fórmulas de liberação } \\
\text { prolongada facilitam a } \\
\text { posologia por serem } \\
\text { ingeridos apenas uma } \\
\text { vez ao dia }\end{array}$ & Louzã e Mattos ${ }^{16}$ & \\
\hline
\end{tabular}




\begin{tabular}{|c|c|c|}
\hline \multicolumn{3}{|l|}{ Quadro 1. continuação } \\
\hline Benefícios para TDAH & Referências & Exemplos \\
\hline $\begin{array}{l}\text { Melhoria na motivação, } \\
\text { coordenação motora, } \\
\text { aprendizado de curto } \\
\text { prazo, atenção, controle } \\
\text { da hiperatividade e } \\
\text { impulsividade. }\end{array}$ & $\begin{array}{l}\text { Scheuer e Andrade }{ }^{17} \\
\text { Pastura e Mattos } \\
\text { Louzã e Mattos }\end{array}$ & \\
\hline $\begin{array}{l}\text { Melhoria do } \\
\text { comportamento }\end{array}$ & Pastura e Mattos ${ }^{12}$ & \\
\hline $\begin{array}{c}\text { Melhoria do } \\
\text { desempenho acadêmico }\end{array}$ & Pastura e Mattos ${ }^{12}$ & \\
\hline Clinicamente seguro & Louzã e Mattos ${ }^{16}$ & $\begin{array}{l}\text { "No Brasil está disponível apenas o metilfenidato, } \\
\text { que é considerado extremamente eficaz, } \\
\text { apresentando um perfil de segurança considerado } \\
\text { satisfatório". (Louzã e Mattos }{ }^{16} \text { ) }\end{array}$ \\
\hline $\begin{array}{c}\text { As fórmulas de liberação } \\
\text { prolongada reduzem o } \\
\text { potencial de abuso }\end{array}$ & Louzã e Mattos ${ }^{16}$ & \\
\hline $\begin{array}{c}\text { Reações adversas "não } \\
\text { sérias" }\end{array}$ & $\begin{array}{l}\text { Carlini et al. }{ }^{13} \text {; Pastura e } \\
\text { Mattos }^{12} \text {; Rohde et al. }{ }^{14}\end{array}$ & \\
\hline $\begin{array}{c}\text { Sono de melhor } \\
\text { qualidade }\end{array}$ & $\begin{array}{c}\text { Louzã e Mattos }{ }^{16} \text {; Regalla } \\
\text { et al. }{ }^{18}\end{array}$ & \\
\hline $\begin{array}{c}\text { Melhoria do } \\
\text { desempenho em testes } \\
\text { de processamento } \\
\text { auditivo em crianças } \\
\text { com TDAH após o uso } \\
\text { da medicação }\end{array}$ & $\begin{array}{c}\text { Schochat et al. }{ }^{19} \text {; Cavadas } \\
\text { et } \mathrm{al}^{20} .\end{array}$ & \\
\hline $\begin{array}{c}\text { Eficaz no tratamento da } \\
\text { comorbidade TDAH- } \\
\text { TID (Transtornos } \\
\text { Invasivos do } \\
\text { Desenvolvimento) }\end{array}$ & $\begin{array}{l}\text { Serenreich e Mattos } \\
\text { Souza et al. }\end{array}$ & $\begin{array}{l}\text { "Ao final, o metilfenidato apresentou eficácia no } \\
\text { tratamento dos sintomas de hiperatividade, embora } \\
\text { a magnitude de resposta tenha sido inferior à } \\
\text { observada em pacientes com TDAH sem TID". } \\
\left(\text { Serenreich e Mattos }{ }^{15}\right)\end{array}$ \\
\hline $\begin{array}{c}\text { Eficaz no tratamento } \\
\text { das seguintes } \\
\text { comorbidades do TDAH: } \\
\text { dislexia, retardo mental } \\
\text { (RM) leve, Transtorno } \\
\text { de Conduta (TC), } \\
\text { Transtorno Desafiador } \\
\text { de Oposição (TDO) }\end{array}$ & $\begin{array}{c}\text { Souza et al. }{ }^{21} ; \\
\text { Serra-Pinheiro et al. }\end{array}$ & $\begin{array}{l}\text { "A eficácia do metilfenidato, comparativamente ao } \\
\text { placebo, na redução dos sintomas de TDAH em } \\
\text { crianças com RM foi documentada em um estudo } \\
\text { conduzido por Pearson". (Souza et al. }{ }^{21} \text { ) }\end{array}$ \\
\hline $\begin{array}{c}\text { Efeito } \\
\text { “antidependência", ou } \\
\text { seja, o metilfenidato } \\
\text { diminui os riscos de } \\
\text { TUSP (Transtorno por } \\
\text { uso de substâncias } \\
\text { psicoativas) }\end{array}$ & $\begin{array}{l}\text { Romano e Szobot }{ }^{23} \text {; } \\
\text { Wilens }^{24} \text {; Carlini et al. }{ }^{13} \text {; } \\
\text { Louzã e Mattos }{ }^{16} \text {; Regalla } \\
\text { et al. }{ }^{18}\end{array}$ & $\begin{array}{l}\text { "Estudos demonstraram que o tratamento com } \\
\text { psicoestimulantes desde a infância proporciona } \\
\text { efeito protetor para o desenvolvimento de TUSP". } \\
\left(\text { Romano e Szobot }^{23}\right)\end{array}$ \\
\hline
\end{tabular}


te aparece nas publicações sempre relacionado à questão se o próprio estimulante causa dependência (Quadro 2).

Nos dois tipos de publicação observou-se concordância a respeito dos benefícios do uso do estimulante na remissão dos sintomas do TDAH, como dificuldades de concentração e impulsividade, resultando em melhoria do desempenho escolar e acadêmico. Também há acordo em relação à boa tolerância do medicamento e ao seu efeito "antidependência", por reduzir os riscos de abuso de drogas na juventude.
Nas publicações leigas, o melhor uso aparece combinado com psicoterapias. Nos periódicos de psiquiatria, o uso do estimulante isoladamente é superior ao uso combinado com terapia.

Nas reportagens voltadas para o grande público, além dos benefícios apresentados, foram encontrados dez depoimentos e relatos de casos que exemplificam os benefícios do uso metilfenidato: crianças que apresentaram melhorias no desempenho escolar após início do uso do medicamento e adultos que melhoraram financeiramente (pelo controle da impulsividade e melhor

Quadro 2. Benefícios do uso do metilfenidato apresentados nas publicações não especializadas.

\begin{tabular}{|c|c|c|}
\hline Benefícios & Referência & Exemplo \\
\hline Redução da impulsividade & $\begin{array}{l}\text { Época, } 05 / 12 / 2003^{26} \\
\text { A Folha, 07/2/1999 } \\
\text { O Globo, } 27 / 7 / 2003^{28}\end{array}$ & $\begin{array}{l}\text { "O redator publicitário Eduardo Mello sofria de } \\
\text { uma impulsividade verbal sem limites. Melhorou } \\
\text { com remédios contra DDA". (Época, 05/12/2003²) }\end{array}$ \\
\hline Redução da ansiedade & Época, $28 / 5 / 2004^{29}$ & \\
\hline $\begin{array}{c}\text { Maior concentração, atenção } \\
\text { e estado de alerta }\end{array}$ & 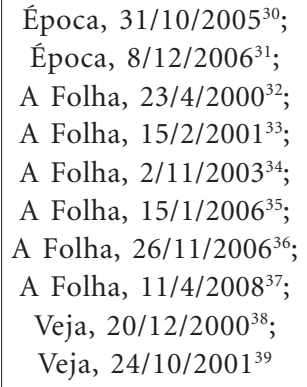 & \\
\hline $\begin{array}{c}\text { Melhoria do desempenho } \\
\text { escolar }\end{array}$ & $\begin{array}{l}\text { Época, } 1 / 12 / 2006^{40} \\
\text { Época, } 6 / 12 / 2006^{41} \\
\text { Época, } 10 / 11 / 2006^{42} \\
\text { Época, } 18 / 12 / 2006^{43} \\
\text { A Folha, } 15 / 2 / 2001^{33} \\
\text { Veja, } 20 / 12 / 2000^{38} \\
\text { Veja, } 24 / 10 / 2001^{39}\end{array}$ & $\begin{array}{l}\text { "O metilfenidato não é a solução, mas permite } \\
\text { que nossas crianças aprendam com menor } \\
\text { sofrimento e desenvolvam relações interpessoais } \\
\text { de melhor qualidade" (Época, 10/11/2006 }\end{array}$ \\
\hline $\begin{array}{c}\text { Redução do risco de abuso de } \\
\text { drogas na juventude e não } \\
\text { vicia }\end{array}$ & $\begin{array}{l}\text { Época, } 05 / 12 / 2003^{26} \\
\text { A Folha, } 15 / 1 / 2006^{35} \\
\text { O Globo, } 31 / 8 / 2003^{44} \\
\text { A Folha, } 25 / 3 / 2004^{45}\end{array}$ & $\begin{array}{l}\text { "O uso da medicação é essencial no tratamento } \\
\text { [de TDAH]. Não causa dependência e até previne } \\
\text { o abuso de substâncias psicoativas" (O Globo, } \\
31 / 8 / 2003^{44} \text { ) }\end{array}$ \\
\hline $\begin{array}{l}\text { Efeito neuroprotetor devido } \\
\text { ao prejuízo que desordens } \\
\text { como o TDAH causam ao } \\
\text { cérebro }\end{array}$ & $\begin{array}{c}\text { Época, 06/12/2006 } \\
\text { A Folha, } 23 / 04 / 2000^{32} ; \\
\text { A Folha, } 15 / 01 / 2006^{35} ; \\
\text { A Folha, } 15 / 2 / 2001^{33} ; \\
\text { A Folha, } 17 / 11 / 2002^{46} ; \\
\text { Veja, } 24 / 10 / 2001^{39}\end{array}$ & \\
\hline
\end{tabular}




\begin{tabular}{|c|c|c|}
\hline Benefícios & Referência & Exemplo \\
\hline $\begin{array}{l}\text { Evita desgaste no } \\
\text { relacionamento familiar e no } \\
\text { comprometimento social }\end{array}$ & A Folha, $12 / 12 / 2006^{47}$ & \\
\hline $\begin{array}{l}\text { O tratamento psicoterápico } \\
\text { de TDAH, combinado ao } \\
\text { medicamento, é superior } \\
\text { clinicamente à psicoterapia } \\
\text { sem o uso do estimulante. }\end{array}$ & O Globo, $31 / 8 / 2003^{44}$ & \\
\hline $\begin{array}{l}\text { A Ritalina é bem tolerada e } \\
\text { não causa efeitos negativos }\end{array}$ & $\begin{array}{l}\text { O Globo, 26/11/2006 } \\
\text { Época, } 05 / 12 / 2003^{26}\end{array}$ & \\
\hline $\begin{array}{l}\text { Pode apresentar resultados } \\
\text { com pessoas com HIV e } \\
\text { fadiga }\end{array}$ & A Folha, 20/2/200149 & $\begin{array}{l}\text { "Os benefícios podem não estar limitados a } \\
\text { pessoas com fadiga relacionada à AIDS". (Folha, } \\
20 / 2 / 2001^{51} \text {, medicamentos podem evitar fadiga) }\end{array}$ \\
\hline $\begin{array}{l}\text { Pode aumentar taxa de } \\
\text { lembrança em pessoas de } \\
\text { todas as idades }\end{array}$ & A Folha, 25/11/2008 & \\
\hline $\begin{array}{l}\text { As fórmulas de liberação } \\
\text { prolongada facilitam a } \\
\text { posologia por serem ingeridos } \\
\text { apenas uma vez ao dia }\end{array}$ & $\begin{array}{l}\text { Época, 28/05/2004 } \\
\text { A Folha, } 25 / 02 / 2004^{51}\end{array}$ & $\begin{array}{l}\text { "O comprimido deve ser tomado uma única vez } \\
\text { ao dia, diferentemente das três doses prescritas } \\
\text { no tratamento convencional. Esse é um grande } \\
\text { avanço porque os pacientes têm dificuldades de } \\
\text { memória [...]". (Época, 28/05/2004 }{ }^{29} \text { ) }\end{array}$ \\
\hline
\end{tabular}

desempenho no trabalho) e nas suas relações amorosas. Estes depoimentos foram incluídos na análise dos benefícios devido à apresentação de vantagens do uso do medicamento como uma melhoria de vida geral do paciente.

Este tipo de depoimento não é encontrado nos artigos científicos. Entretanto, no material fornecido pela Novartis à classe médica, inclui-se uma "Separata do artigo Conhecimento sobre o TDAH no Brasil” com a capa do Jornal Brasileiro de Psiquiatria ${ }^{52}$. Dentro desta "separata do artigo”, foi incluído um texto que não está presente no JBP, que apresenta a Associação Brasileira do Déficit de Atenção (ABDA) e relata depoimentos de associados.

Estes relatos, apresentados aos médicos, são muito semelhantes aos encontrados nas reportagens publicadas nos jornais e revistas de grande circulação:

Beto: Ele era uma criança levada, que não parava no lugar e não se concentrava em nada. Diziam que ele era hiperativo[...]. Ele já estava tornando-se um adulto e por meio do destino sua mãe conheceu um médico que tratava de um tal déficit de atenção.
[...] Ele tomou a medicamento sem crença nenhuma naquilo. [...] Hoje ele é feliz, tem uma namorada, estuda o que gosta, tem muitos amigos, sua família se orgulha dele e, acima de tudo, ele próprio sabe o que tem e vive feliz com a sua realidade.

Este tipo de material difere do formato dos periódicos de psiquiatria. Contudo, os autores dos periódicos analisados são os mesmos que escrevem os textos do material distribuído de forma promocional aos médicos pelos laboratórios fabricantes de metilfenidato no Brasil.

\section{Efeitos adversos apresentados}

Nesta categoria, foram incluídos os efeitos adversos que foram apresentados nas publicações. Incluem-se o risco de dependência e o risco de abuso do medicamento por parte do paciente.

Nos 31 periódicos de psiquiatria, treze abordam os efeitos colaterais do medicamento (41\%). Os efeitos colaterais que ocorrem com maior frequência também são abordados mais vezes nas publicações (Quadro 3).

Efeitos adversos com ocorrência mais frequente: dores de cabeça, redução do apetite e con- 
sequente perda de peso, insônia, dores abdominais e redução do crescimento. Efeitos adversos com ocorrência menos frequente: dependência, aumento da irritabilidade em pacientes com TDAH, piora dos sintomas de hiperatividade, náusea, taquicardia, aumento da ansiedade e potencial de abuso do medicamento.

Os efeitos adversos mais comuns são considerados dose-dependentes por quase todos os autores, ou seja, com a suspensão do medicamento, o sintoma desaparece. Alguns dos efeitos desaparecem ao longo do tratamento ${ }^{12}$.

O risco de abuso do medicamento só é citado nas publicações a partir de 2004. As formulações de liberação prolongada são indicadas em todas estas publicações por serem mais seguras e diminuírem o potencial de abuso por parte do paciente. Pelo exposto, acredita-se que o lançamento do metilfenidato de ação prolongada no Brasil em 2004 tenha contribuído para o surgimento desta discussão, visto que todos os quatro artigos que abordam o potencial de abuso são de autoria de palestrantes e consultores da empresa fabricante deste medicamento.

Nas reportagens voltadas para o público em geral, os efeitos adversos relatados condizem, de modo geral, com aqueles publicados nos periódicos de psiquiatria. Das 72 reportagens analisadas, dezesseis (22\%) apresentam alguns dos efeitos colaterais do uso do metilfenidato (Quadro 4).

Quadro 3. Efeitos colaterais do uso do metilfenidato apresentados nas publicações científicas.

\begin{tabular}{|c|c|c|}
\hline $\begin{array}{c}\text { Efeitos colaterais com } \\
\text { ocorrência mais frequente }\end{array}$ & Referência & Exemplo \\
\hline Dor de cabeça & 8 artigos & \\
\hline $\begin{array}{l}\text { Redução do apetite e } \\
\text { consequente perda de peso }\end{array}$ & 9 artigos & \\
\hline Insônia & 7 artigos & \\
\hline Dores Abdominais & 4 artigos & \\
\hline Redução do crescimento & 5 artigos & $\begin{array}{l}\text { Alguns afirmam que a diferença da altura é temporária e } \\
\text { não altera a estatura final (Scheuer e Andrade }{ }^{17} \text {; Rohde et } \\
\left.\text { al. } .^{14}\right) \text {. Alguns sugerem que "este atraso [de crescimento] se } \\
\text { relaciona ao TDAH e não ao estimulante" (Scheuer e } \\
\text { Andrade }^{17} \text {; Pastura e Mattos }{ }^{12} \text { ). }\end{array}$ \\
\hline $\begin{array}{c}\text { Efeitos colaterais com } \\
\text { ocorrência menos frequente }\end{array}$ & Referência & Exemplo \\
\hline Dependência & 3 artigos & $\begin{array}{l}\text { Somente em casos de uso crônico. Mas a dependência é } \\
\text { raramente observada. (Pastura e Mattos }{ }^{12} \text { ) }\end{array}$ \\
\hline $\begin{array}{l}\text { Aumento da irritabilidade } \\
\text { em pacientes com TDAH }\end{array}$ & 3 artigos & \\
\hline $\begin{array}{l}\text { Piora dos sintomas de } \\
\text { hiperatividade }\end{array}$ & 4 artigos & \\
\hline Náusea & 3 artigos & \\
\hline Taquicardia & 4 artigos & \\
\hline Aumento da ansiedade & 5 artigos & \\
\hline $\begin{array}{l}\text { Potencial de abuso do } \\
\text { medicamento }\end{array}$ & 4 artigos & $\begin{array}{l}\text { Para redução do potencial de abuso do medicamento é } \\
\text { sugerido o metilfenidato de ação prolongada. }\end{array}$ \\
\hline
\end{tabular}


Quadro 4. Efeitos colaterais do uso do metilfenidato apresentados nas publicações não especializadas.

\begin{tabular}{|c|c|c|}
\hline $\begin{array}{l}\text { Efeitos colaterais encontrados } \\
\text { com mais frequência pelos } \\
\text { especialistas }\end{array}$ & Referência & Detalhes \\
\hline Dor de cabeça & 6 publicações & \\
\hline $\begin{array}{l}\text { Redução do apetite e consequente } \\
\text { perda de peso }\end{array}$ & 12 publicações & \\
\hline Insônia & 13 publicações & \\
\hline Dor de estômago & 5 publicações & \\
\hline Redução do crescimento & 3 publicações & $\begin{array}{l}\text { "Em alguns casos ela inibe o crescimento, por isso } \\
\text { não é recomendada para menores de três anos". } \\
\left(\text { A Folha, } 15 / 02 / 2001^{33} \text { ) }\right.\end{array}$ \\
\hline $\begin{array}{l}\text { Efeitos colaterais mais } \\
\text { raramente encontrados pelos } \\
\text { especialistas }\end{array}$ & Referência & Detalhes \\
\hline $\begin{array}{l}\text { Aumento da ansiedade e } \\
\text { hiperatividade }\end{array}$ & 3 publicações & \\
\hline Aumento da irritabilidade & 2 publicações & \\
\hline Depressão e melancolia & 5 publicações & \\
\hline $\begin{array}{l}\text { Risco de doenças cardiovasculares } \\
\text { e hipertensão. Parada Cardíaca. }\end{array}$ & 4 publicações & \\
\hline $\begin{array}{l}\text { Prejuízo à região frontal do } \\
\text { cérebro }\end{array}$ & 2 publicações & \\
\hline Dependência & 3 publicações & \\
\hline Dependência psicológica & 2 publicações & $\begin{array}{l}\text { "O maior perigo da banalização do diagnóstico e } \\
\text { do tratamento do TDAH é a dependência } \\
\text { psicológica ao remédio (...). A criança passa a } \\
\text { acreditar que precisa tomar o comprimido para } \\
\text { ficar boazinha e sente-se insegura em deixar de } \\
\text { usar o medicamento" (A Folha, } 15 / 01 / 2001^{53} \text { ) }\end{array}$ \\
\hline
\end{tabular}

Os artigos científicos apresentam mais detalhes sobre os efeitos adversos. Nas reportagens leigas, os efeitos adversos são apresentados, sobretudo, nas publicações que se posicionam explicitamente contra o uso do medicamento.

Efeitos adversos sérios como dependência e riscos cardiovasculares são apresentados como efeitos do uso crônico do medicamento. Além disso, a cronificação do próprio TDAH coloca em questão o tempo de uso do medicamento e seus efeitos. A questão da duração do uso do medicamento quase não é abordada, nem nas publicações científicas, nem nas reportagens destinadas ao público em geral. Em todas as publicações foram observados apenas três frases que abordam o tempo do tratamento.

No caso da única frase dos periódicos de psiquiatria, o que está em jogo é apenas uma possível suspensão do uso do medicamento: $A$ indicação para a suspensão parece ocorrer quando o paciente apresenta um período de cerca de um ano assintomático, ou quando há melhora importante da 
sintomatologia. Suspende-se o medicamento para avaliação da necessidade de continuidade de uso ${ }^{14}$.

As outras duas frases das publicações leigas são mais precisas quanto à duração do tratamento: Em relação à dependência física, os especialistas atestam que não há riscos, desde que o remédio tenha indicação precisa e por tempo determinado - em média, durante dois anos ${ }^{54}$, e As drogas, como as de base de Ritalina, são indicadas [...] só em casos raríssimos de extrema dificuldade de concentração e devem ser usadas em períodos de um a dois anos no máximo ${ }^{55}$.

O risco de dependência é citado em três publicações científicas, todas as publicações sugerem um fenômeno raramente observado, um risco mais teórico que prático ${ }^{12}$.

Nas publicações direcionadas para o público em geral, três reportagens apresentam discursos que consideram a dependência um risco, e outras quatro afirmam que este risco não existe. As opiniões apresentadas variam entre dois extremos: ou a dependência é um mito ${ }^{54}$, ou o metilfenidato se situa na mesma categoria farmacológica de alto potencial de vício que a cocaina e as anfetaminas ${ }^{56}$.

O tema do potencial de dependência do metilfenidato leva, em geral, à argumentação sobre o potencial de abuso de drogas ilícitas. O metilfenidato não somente não causaria dependência, para alguns autores, como evitaria dependência de substâncias ilícitas. Não foram encontradas pesquisas apresentando resultados que comprovem esta afirmação.

A cronificação do transtorno, a importância do tratamento medicamentoso e os efeitos adversos do uso do medicamento em longo prazo nunca são apresentados em uma mesma discussão. Para alguns autores, $70 \%$ dos casos de TDAH permanecem na vida adulta ${ }^{17}$ ou mesmo 90\% dos $\operatorname{casos}^{56}$.

Partindo para o último ponto de análise nas publicações sobre o metilfenidato no Brasil: existiria um excesso de prescrições? Ou, na verdade, o número de pessoas medicadas com metilfenidato estaria abaixo da necessidade real? O que as publicações brasileiras dizem a respeito?

\section{Existe excesso de prescrição}

de metilfenidato no Brasil?

Esta categoria de análise inclui as discussões apresentadas nas publicações sobre um possível excesso ou escassez de prescrições do metilfenidato no Brasil.

Dos 31 artigos científicos analisados, apenas três $(9,6 \%)$ abordam o problema. Todos ${ }^{13,57,58}$ concordam que no Brasil, além de não haver ex- cesso de diagnóstico, o que há é uma escassez de pessoas diagnosticadas. É interessante notar que, nestes artigos, o diagnóstico e o medicamento se equivalem.

Um artigo assinado por dois funcionários da Novartis e dois outros pesquisadores ${ }^{13}$ apresenta o número de brasileiros que seriam usuários em potencial do medicamento:

O pequeno número de pacientes brasileiros que recebem o metilfenidato merece maiores reflexões [...]. No Brasil, a prevalência da sindrome está avaliada entre 3\% a 6\%. Por outro lado, a população entre 12 e 17 anos está calculada em aproximadamente 28 milhões [...]. Portanto, o número de crianças e adolescentes, com idade entre 12 e 17 anos com TDAH deveria oscilar entre $840.000 e$ 1.680 .000 de pacientes. Depreende-se daí que o número de 7.413 pacientes que recebem o metilfenidato em julho de 2001 é extremamente pequeno em relação ao universo brasileiro [...].

Embora o uso do metilfenidato esteja associado diretamente ao diagnóstico de TDAH, ela não é recomendada em todos os casos onde o transtorno é diagnosticado. Na bula do metilfenidato, na seção "precauções", o fabricante afirma que o uso do medicamento não é indicado em todos os casos de TDAH e deve ser considerado somente após levantamento detalhado da história e da avaliação da criança ${ }^{59}$.

Das 72 reportagens analisadas, 35 abordam a questão de um possível excesso (ou escassez) de prescrições médicas $(48,6 \%)$. Todas as 35 reportagens afirmam que existe um excesso de prescrições. O excesso de prescrições estaria acontecendo, segundo estas reportagens, porque crianças que não possuiriam o transtorno estariam sendo medicadas, ou porque todos os casos de TDAH estariam sendo medicados, sem necessidade.

Nas trinta e cinco reportagens que afirmam que há um excesso de prescrição de metilfenidato, todas se referem ao uso do medicamento por crianças. Destas 35, apenas cinco reportagens também apresentam a opinião de especialistas que afirmam que o aumento do diagnóstico é o principal fator de aumento da prescrição do medicamento.

Nos dois tipos de publicação é reconhecido o aumento do consumo de metilfenidato no Brasil. Entretanto, as explicações para tal aumento são praticamente opostas. Nos artigos científicos, o aumento é natural, devido ao aumento de casos diagnosticados.

Certamente, o TDAH tem se tornado um diagnóstico cada vez mais conhecido, o que pode ocasionar em maior número de pessoas que se 
beneficiariam dos efeitos do medicamento. Contudo, chama atenção que quase a metade de todas as reportagens publicadas sobre o estimulante no Brasil apresente o excesso de um modo que é inexistente nos periódicos de psiquiatria: um excesso médico.

\section{Considerações finais}

Como foi exposto, o metilfenidato é comercializado desde os anos 50, mas apenas nas últimas décadas sua produção e consumo mundiais se ampliaram consideravelmente. A associação de seu uso ao diagnóstico de TDAH e sua divulgação para o público são os principais fatores que justificam o crescimento das vendas.

O objetivo deste trabalho foi compreender de que modo a divulgação deste psicoestimulante foi realizada entre 1998 e 2008 no Brasil, tendo como foco os periódicos de psiquiatria e os meios de comunicação impressa destinados ao público em geral.

\section{Colaboradores}

C Itaborahy trabalhou na concepção, redação do texto e na pesquisa que dá subsídio ao artigo e $\mathrm{F}$ Ortega participou da concepção do texto, orientou a pesquisa teórica e empírica que fundamenta o artigo, e trabalhou na revisão final do texto.
$\mathrm{Na}$ análise dos artigos de psiquiatria, destaca-se como ponto relevante a predominância de artigos sobre o uso do medicamento para tratamento do TDAH, e a importante participação dos laboratórios no financiamento dos grupos e pesquisas sobre este diagnóstico. A narcolepsia é citada em uma publicação apenas. Além disso, foi observado que, nas reportagens destinadas ao grande público, as pesquisas internacionais são mais valorizadas, não tendo sido encontrado nenhum resultado de pesquisas nacionais nestas publicações.

Existe concordância a respeito dos principais benefícios e efeitos adversos nos dois tipos de publicação. A combinação do uso do medicamento com psicoterapias, e a dependência do medicamento são temas controversos nas publicações analisadas, assim como a ideia de que existe excesso de prescrição no Brasil.

Diante do exposto, entende-se que esta pesquisa contribui para a compreensão da percepção social do metilfenidato no Brasil e o modo como este psicoestimulante vem sendo divulgado e consumido no país.

\author{
-
}




\section{Referências}

1. Dupanloup A. L'Hyperactivité infantile: analyse sociologique d'une controverse socio-médicale [tese]. Neuchâtel: Universidade de Neuchâtel; 2004.

2. Brasil. Agência Nacional de Vigilância Sanitária. [mensagem pessoal]. Mensagem recebida em 19 de agosto de 2008.

3. Almeida SC, Rayes A, Tavares A, Lambertucci JR. O emprego de psicoestimulantes em adultos. J Bras Psiquiatr 1997; 46(7):377-383.

4. International Narcotics Control Board. Psychotropic substances: statistics for 2006, assessments of annual medical and scientific requirements for substances. New York: United Nations; 2008. [acessado 2008 dez 02]. Disponivel em: http://www.incb.org

5. Diller H. The run on Ritalin: attention deficit disorder and stimulant treatement in the 1990's. Hastings Cent. Rep 1996; 2:2-8.

6. Lima R. Somos todos desatentos? - O TDA/H e a construção de bioidentidades. Rio de Janeiro: Relume-Dumará; 2005.

7. Agencia Nacional de Jornais. Os maiores jornais do Brasil. 2008. [acessado $2008 \mathrm{dez}$ 15]. Disponível em: http://www.anj.org.br

8. Bittencourt LRA, Silva RS, Santos RF, Pires MLN, Mello MT. Sonolência Excessiva. Rev Bras Psiquiatr 2005; 27(Supl. 1):16- 21.

9. Lucchesi LM, Pradella-Hallinan M, Lucchesi M, Moraes WAS. O sono em transtornos psiquiátricos. Rev Bras Psiquiatr 2005; 27(Supl. 1):27-32.

10. Rocha FL, Malloy-Diniz LF, Hara C. Emprego do metilfenidato para o tratamento de déficit cognitivo em paciente com sequela de traumatismo cranioencefálico. J Bras Psiquiatr 2006; 55(1):78-81.

11. Teixeira Júnior AL, Caramelli P. Apatia na doença de Alzheimer. Rev Bras Psiquiatr 2006; 28(3):238241.

12. Pastura G, Mattos P. Efeitos adversos do metilfenidato. Rev Psiquiatr Clín 2004; 31(2):100-104.

13. Carlini E, Nappo S, Nogueira V, Naylor F. Metilfenidato: influência da notificação de receita A (cor amarela) sobre a prática de prescrição por médicos brasileiros. Rev Psiquiatr Clín 2003; 30(1):11-20.

14. Rohde LA, Barbosa G, Tramontina S, Polanczyk G. Transtorno de déficit de atenção/ hiperatividade. Rev Bras Psiquiatr 2000; 22(Supl. 2):7-11.

15. Serenreich D, Mattos P. Atualização sobre comorbidade entre transtorno do déficit de atenção e hiperatividade (TDAH) e transtornos invasivos do desenvolvimento (TID). Rev Bras Psiquiatr 2007; 34(4):184-190.

16. Louzã MR, Mattos P. Questões atuais no tratamento farmacológico do TDAH em adultos com metilfenidato. J Bras Psiquiatr 2007; 56(Supl. 1): 53-56.

17. Scheuer C, Andrade E. Análise da eficácia do metilfenidato usando a versão abreviada do questionário de conners em Transtorno de Déficit de Atenção/Hiperatividade. Arq Neuropsiquiatr 2004; 62(1): 81-85.

18. Regalla MA, Guilherme PR, Serra-Pinheiro MA. Resiliência e transtorno do déficit de atenção/hiperatividade. J Bras Psiquiatr 2007; 56(Supl. 1):45-49.
19. Schochat E, Scheuer CI, Andrade ER. ABR and Auditory P300 findings in children with ADHD. Arq Neuropsiquiatr 2002; 60(3-B):742-747.

20. Cavadas M, Pereira LD, Mattos P. Efeito do metilfenidato no processamento auditivo em crianças e adolescentes com TDAH. Arq Neuropsiquiatr 2007; 65(1):138-143.

21. Souza IGS, Serra-Pinheiro MA, Fortes D, Pinna C. Dificuldades no diagnóstico de TDAH em crianças. J Bras Psiquiatr 2007; 56(Supl. 1):14-18.

22. Serra-Pinheiro MA, Mattos P, Souza I, Pastura G, Gomes F. The effect of Methylphenidate on Oppositional Defiant Disorder comorbid with Attention Deficit/ Hyperactivity Disorder. Arq Neuropsiquiatr 2004; 62(2-B):339-402.

23. Romano M, Szobot C. Co-ocorrência entre transtorno de déficit de atenção/hiperatividade e uso de substâncias psicoativas. J Bras Psiquiatr 2007; 56(Supl. 1):39-44.

24. Wilens T. Does the medicating ADHD increase or decrease the risk for later substance abuse? Editorial. Rev Bras Psiquiatr 2003; 25(3):127-128.

25. Associação Médica Brasileira. Conselho Federal de Medicina. Projeto Diretrizes - Abuso e Dependência Anfetamina. 2002. [acessado 2008 out 18]. Disponível em: http://www.projetodiretrizes.org.br/projeto_ diretrizes/003.pdf

26. Segatto C, Manir M, Termero M. Prisioneiros das pílulas. Revista Época 2003; Dez 05 Ed. 290. [acessado 2008 nov 22]. Disponível em: http://revista epoca.globo.com/Revista/Epoca/0,,EDG61656$6014,00 . h$ tml

27. Distúrbio afeta $4 \%$ das crianças. Folha de São Paulo 1999 jul 07. [acessado 2008 nov 15]. Disponível em: http://www.folha.uol.com.br/

28. Fernandes L, Cezimbra M. A criança índigo - a vida contemporânea atinge crianças sensíveis. $O$ Globo 2003 jul 27. [acessado 2008 nov 22]. Disponível em: http://oglobo.globo.com

29. Segatto C. Mais perto do chão: Novo remédio contra hiperatividade facilita o tratamento de quem vive no mundo da lua. Revista Época 2004 mai 28. Ed. 315. [acessado 2008 nov 22]. Disponível em: http:// revistaepoca.globo.com/Revista/Epoca/0,,EDR 64577-6014,00.html

30. Clemente AT, Veida A. Receitas para a inteligência. Revista Época 2005 out 31. Ed. 389. [acessado 2008 nov 22]. Disponível em: http://revistaepoca.globo. com/Epoca/0,6993,EPT1062522-1664-1,00.html

31. Andrews S. Tocar é educar. Revista Época $2006 \mathrm{dez}$ 08. Ed. 447. [acessado em 2008 nov 23]. Disponível em: http://revistaepoca.globo.com/Revista/Epoca/ 0,„EDG75920-6048-447,00.html

32. Barbosa Jr A. Déficit de Atenção também atinge adultos. Folha de São Paulo 2000 abr 23. [acessado em 2008 nov 23]. Disponível em: http://www1.folha. uol.com.br/fsp/cotidian/ff2304200017.htm

33. Falcão D. Hiperatividade confunde pai, professor e médico. Folha de São Paulo 2001 fev 15. [acessado em 2008 nov 23]. Disponível em: http://www1.folha. uol.com.br/fsp/equilibrio/eq1502200101.htm 
34. Frederico C. "Avoado" tem distúrbio se há dano social. Folha de São Paulo 2003 nov 02. [acessado em 2008 nov 23]. Disponível em: http://www1. folha.uol.com.br/fsp/cotidian/ff0211200313.htm

35. Collucci C. Diagnóstico errado leva a excesso de remédio Folha de São Paulo 2006 jan 15. [acessado 2008 nov 20]. Disponível em: http://wwwl.folha. uol.com.br/fsp/cotidian/ff1501200609.htm

36. Harris G. Hipermedicação de crianças alarma EUA. Folha de São Paulo 2006 nov 26. [acessado em 2008 nov 23]. Disponível em: http://www1.folha.uol. com.br/fsp/mundo/ft2611200608.htm

37. Garcia R. Cientista usa drogas para turbinar desempenho. Folha de São Paulo 2008 abr 11. [acessado em 2008 nov 23]. Disponível em: http://www1. folha.uol.com.br/folha/ciencia/ult306u391158.shtml

38. Colaviti F. Eles são da pá virada. Revista Veja 2000 dez 20. [acessado em 2008 nov 23]. Disponível em: http://veja.abril.com.br/201200/p_198.html

39. Morais AS. Sossega Menino! Revista Veja 2001 out 24. [acessado em 2008 nov 23]. Disponível em: http:/ /veja.abril.com.br/241001/p_095.html

40. Os riscos da infância medicada. Carta dos leitores. Revista Época $2006 \mathrm{dez}$ 08. Ed. 447. [acessado em 2008 set 20]. Disponível em: http://revista epoca. globo.com/Revista/Epoca/0,,EMI55855-15219,00OS+RISCOS+DA+INFANCIA +MEDICADA.html

41. Segatto C, Padilla I, Frutuoso S. Na selva de remédios. Revista Época $2006 \mathrm{dez}$ 06. Ed. 446. [acessado 2008 nov 22]. Disponível em: http://revista epoca. globo.com/Revista/Epoca/1,,EDG75898-6014,00. html

42. A polêmica da Hiperatividade. Leitores de Época comentam o artigo da colunista Susan Andrews. Revista Época 2006; 443(10). [acessado 2008 nov 22]. Disponível em: http://revistaepoca.globo.com/Revista/Epoca

43. Segatto C, Padilla I, Frutuoso S. Remédios demais? Revista Época $2006 \mathrm{dez}$ 18. [acessado 2008 nov 22]. Disponível em: http://revistaepoca.globo.com/Revista/Epoca/1,,EDG75898-6014,00.html

44. Barbirato F. Como tratar a hiperatividade e o déficit de atenção. O Globo 2003 ago 31. [acessado 2008 set 20]. Disponível em: http://oglobo.globo.com

45. Droga em nova versão ajuda o hiperativo. Folha de São Paulo 2004 mar 25. [acessado em 2008 nov 23]. Disponível em: http://www1.folha.uol.com.br/fsp/ equilibrio/eq2503200404.htmJornal Brasileiro de Psiquiatria. Rio de Janeiro: IPUB; 2007.

46. Marchiori B. Adulto "elétrico" pode ter distúrbio. Folha de São Paulo 2002 nov 17. [acessado em 2008 nov 23]. Disponível em: http://wwwl.folha. uol. com.br/fsp/cotidian/ff1711200217.htm

47. Biderman I, Rossi P. Muita calma nessa hora. Folha de São Paulo $2006 \mathrm{dez}$ 12. [acessado em 2008 nov 23]. Disponível em: http://wwwl.folha.uol.com.br/ fsp/equilibrio/eq1210200608.htm
48. Faveret E. Atenção. O Globo 2006 nov 26. [acessado 2008 set 20]. Disponível em: http://oglobo.globo. com

49. Estimulantes podem evitar fadiga relacionada à AIDS. Folha de São Paulo 2001 fev 20. [acessado em 2008 nov 23]. Disponível em: http://www.folha. uol.com.br

50. Garcia R. Medicamento para atenção ajuda a reter a memória. Folha de São Paulo 2008 nov 25. [acessado em 2008 nov 23]. Disponível em: http://wwwl. folha.uol.com.br/folha/ciencia/ult306u471258.shtml

51. Klinger K. Adultos também sofrem com a hiperatividade. Folha de São Paulo $2004 \mathrm{fev}$ 25. [acessado em 2008 nov 23]. Disponível em: http://www1. folha.uol.com.br/folha/equilibrio/noticias/ult263u 3487.shtml

52. Jornal Brasileiro de Psiquiatria. Rio de Janeiro: IPUB; 2007.

53. Falcão D. O uso de Ritalina é polêmico. Folha de São Paulo 2001 jan 15. [acessado em 2008 nov 23]. Disponível em: http://wwwl.folha.uol.com.br/fsp/ equilibrio/eq1502200104.htm

54. Tofoli D. País vive febre da "droga da obediência". Folha de São Paulo 2006; 15 jan. [acessado 2008 nov 20]. Disponível em: http://www.folha.uol.com.br

55. Andrews S. A doença fantasma. Revista Época 2006; nov(441). [acessado 2008 nov 2008]. Disponível em: http://revistaepoca.globo.com/Revista/Epoca/ 0,„EDG75609-6048-441,00.html

56. Grevet E, Abreu P, Shansis F. Proposta de uma abordagem psicoeducacional em grupos para pacientes adultos com transtorno de déficit de atenção/hiperatividade. Rev Psiquiatr RS 2003; 25(3):446-452.

57. Mattos P. Transtorno de déficit de atenção e hiperatividade (TDAH) na prática clínica. [editorial]. J Bras Psiquiatr 2007; 56(Supl. 1):5.

58. Gomes M, Palmini A, Barbirato F. Conhecimento sobre o transtorno do déficit de atenção/hiperatividade no Brasil. J Bras Psiquiatr 2007; 56(Supl. 1):94-101.

59. Ritalina: metilfenidato. São Paulo: Novartis; 1998. (Bula de remédio)

Artigo apresentado em 08/09/2011

Aprovado em 10/10/2011

Versão final apresentada em 13/10/2011 